\title{
Study of Association Between TLR4 D299G and T399I Polymorphisms and Risk of Gastric Cancer
}

DOI: 10.30699/acadpub.mci.2.3.25

Hasan Hatami ${ }^{1}$, Hamed Naghoosi ${ }^{1}$, Mahyar Nourian ${ }^{1}$, Mostafa Iranpour ${ }^{1}$, Sandra Saidi ${ }^{1}$, Mahmoud Reza Hashemi ${ }^{1}$, Shahrokh Iravani ${ }^{1 \text {,** }}$

${ }^{I} A J A$ Cancer Epidemiology Research and Treatment Center (AJA-CERTC), AJA University of Medical Sciences, Tehran, Iran

*Corresponding authors: Shahrokh Iravani, AJA Cancer Epidemiology Research and Treatment Center (AJA-CERTC), AJA University of Medical Sciences, Tehran, Iran.Tel: +982143823478; Fax:+982143822994; E-mail: iravani.shahrokh@yahoo.com

Submitted: 27 Feb 2018

Revised:19 May 2018

Accepted: 10 June 2018

e-Published: 1 July 2018

Keywords:

Stomach Neoplasms

TLR4

Polymorphism

Single Nucleotide

\begin{abstract}
Introduction: Gastrointestinal cancers constitute more than one-third of the most common cancers and half of the fatal cancers worldwide. Toll-like receptors (TLRs) are identified as pivotal receptors in innate immunity responses. TLR4 is the main receptor that plays a role in lipopolysaccharide (LPS) sensing of gram-positive bacteria. D299G (rs4986790) and T399I (rs4986791) polymorphisms in TLR4 lead to a decrease in immune response against LPS. The current study aimed at investigating the relationship between D299G and T399I polymorphisms and susceptibility to gastritis and gastric precancerous lesions in patients referred to Imam Reza Hospital, Tehran, Iran.

Methods: The current case-control study was conducted on 201 individuals consisting of 90 patients with gastric cancer (GC) and 111 healthy controls. Genomic DNA was extracted from peripheral blood and the polymerase chain reaction-restriction fragment length polymorphism (PCR-RFLP) method was used to determine the mentioned polymorphisms.

Results: Allelic frequencies and genetic distribution of polymorphisms were analyzed in the patient and control groups. Although 399C and 299A allele frequencies were higher in the patients' group, the difference was not statistically significant $(\mathrm{P}>0.05)$.

Conclusions: No significant association was observed between TLR4 polymorphisms on positions 299 and 399, and susceptibility to GC. Also no significant correlation was observed between these two polymorphisms and precancerous lesions. The current study results showed that the studied polymorphisms cannot be used as a prognostic marker of GC in Iranian population.
\end{abstract}

(C) 2018. Multidisciplinary Cancer Investigation

\section{INTRODUCTION}

Gastrointestinal cancers constitute more than onethird of the most common cancers and half of the fatal cancers worldwide [1]. According to the global statistics in contrast to a significant decline in gastric cancer (GC) in European countries, there is an increasing trend in most of the developing countries, such as South Korea, Iran, and Portugal [2-6]. Many factors, such as diet, smoking, family history, presence of precancerous lesions and polyps, and most importantly chronic Helicobacter pylori (H. pylori) infection can contribute to developing GC [7]. Genetic studies show that there is a wide range of human genes whose function is directly or indirectly involved in the incidence and severity of GC manifestations [5]. Toll-like receptors (TLRs) are a group of trans-membrane proteins involved 
in immune responses against different conditions, including H. pylori infection [8]. Among the TLR family members, TLR4 was the first receptor identified and characterized in humans [9]. Previous studies indicated that TLR4 increases in gastric epithelial cells infected with $H$. pylori, and its expression is observed in active chronic gastritis, premalignant lesions, and GC $[10,11]$. Activation of the immune system and inflammation are regulated by single-nucleotide polymorphisms (SNPs) and there is considerable evidence of their important role in cancer progression $[6,10]$. TLR4 is one of the most active members of TLRs family involved in the immune system activation process [12]. Some genetic polymorphisms in the TLR4 gene have a significant impact on the predisposition of infectious diseases, allergies, cardiovascular diseases, and cancers [13]. For example, the lipopolysaccharides (LPSs) of $\mathrm{H}$. pylori and other Gram-negative bacteria are the TLR4-target molecules, and thus, it is thought that TLR4 polymorphism play a role in H. pylori related diseases [14]. Two SNPs are reported on chromosome 9, which are associated with gastrointestinal cancers. One of these SNPs is an aspartic acid for a glycine at position 299 (Asp299Gly) and the other is threonine for an isoleucine at position 399 (Thr399Ile) [15-17]. Several studies declare a correlation between these two SNPs and gastric inflammation [17, 18]. These two polymorphisms (Asp299Gly \& Thr399Ile) cause changes in the receptor structure at the extracellular surface, which stops responding to LPSs under laboratory and normal conditions [19, 20].

The current study aimed at investigating the effect of TLR4 gene polymorphisms (Asp299Gly \& Thr399Ile) on susceptibility to gastritis and gastric precancerous lesions in patients referred to Imam Reza Hospital.

\section{METHODS}

\section{Study Subjects}

The current case-control study was conducted on 201 individuals consisting of 90 patients with gastritis and GC referred to the Gastrointestinal and Liver Disease Section, Department of Internal Medicine, Imam Reza Hospital (Tehran, Iran) and 111 healthy controls from 2014 to 2015 . Genomic DNA was extracted from peripheral blood and the polymerase chain reaction-restriction fragment length polymorphism (PCR-RFLP) method was employed to determine Asp299Gly and Thr399Ile polymorphisms. Written informed consent was obtained from participants prior to enrolling in the study; the study was approved by the AJA Medical University Ethics Committee. The inclusion criterion for patients' was the confirmed diagnosis of gastritis by endoscopy and pathologic findings.

\section{DNA Extraction}

A 4-mL peripheral blood was poured into ethylenediaminetetraacetic acid (EDTA) tubes and genomic DNA was extracted using saltingout method [21]. Purity of the extracted DNAs was assessed using a UV spectrophotometer. The ratio of absorbance at 260 and $280 \mathrm{~nm}$ was used to assess protein contamination. Spectrophotometric measurements constitute criteria for DNA quality assessment with higher values associated with better DNA purity. Then, the samples were pipetted into $1.5-\mathrm{mL}$ microtubes and stored at $-70^{\circ} \mathrm{C}$.

\section{Genotyping}

The TLR4 promoter specific primers were designed using Primer3, Gen Runner, and NCBI Primer Blast software. Designed primers were purchased from Sigma-Aldrich (Germany) (Table1).

PCR was amplified using the extracted DNA and specific primers. The materials used in the PCR mixture were as follows: $2.5 \mu \mathrm{L}$ of buffer $10 \mathrm{X}$ containing $\mathrm{MgCl} 2,0.5 \mu \mathrm{L}$ of $0.2 \mathrm{mM}$ dNTP both reverse and forward (GenFanavaran- Iran), $5 \mathrm{pM}$ of each primer (Bioneer- Korea), $1.25 \mu \mathrm{L}$ (5\% of the total reaction volume) of dimethyl sulfoxide (Sigma-Germany), and 2.5 U of Taq polymerase enzyme (SuperTaqGenFanavaran- Iran). The prepared mixture was then placed in a thermal cycler machine (EppendorfGermany). The prepared samples were placed into the thermal cycler to run for one minute at $95^{\circ} \mathrm{C}$ as initial activation step followed by 30 cycles at $95^{\circ} \mathrm{C}$ for 30 seconds, $60^{\circ} \mathrm{C}$ for one minute, and $72^{\circ} \mathrm{C}$ for one minute. In the next step, the PCR products were digested with restriction enzymes (Thermo Scientific-USA) by PCRRFLP method (Table 1). The mixture was incubated at $37^{\circ} \mathrm{C}$ for $16-18$ hours for enzymatic digestion. Then, the PCR-RFLP products were electrophoresed on 3\% agarose gel.

\section{Statistical Analysis}

Data were analyzed with SPSS version 20. The allelic distribution was evaluated using the Hardy-Weinberg equilibrium in the patient and control groups, by the 


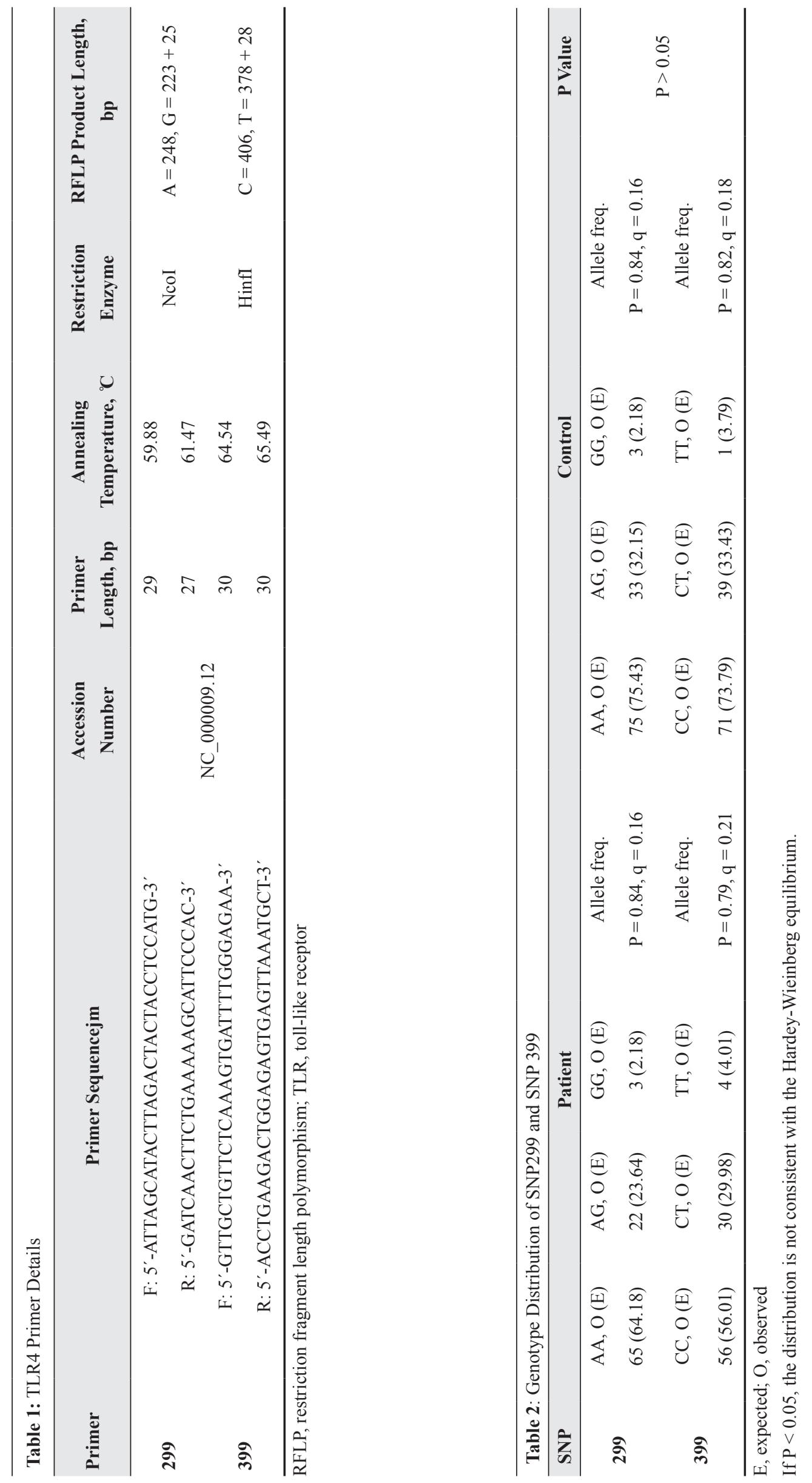


standard method as described by Rodriguez et al., [22]. Comparison of genotypic and allelic frequencies was performed using Chi-square test. $\mathrm{P}<0.05$ was considered statistically significant. The Student $t$ test was used to compare quantitative variables including age and body mass index (BMI) between the study groups. The sensitivity and specificity of the TLR4 gene polymorphism, as a biomarker for $\mathrm{GC}$, was investigated using ROC curve.

\section{RESULTS}

All samples used in the study were from Iranian people and other nationalities, including Afghans, were excluded from the study. Of the 201 samples enrolled in the study, 111 were allocated to the control group and 90 to the patient group. The genotype distribution was at Hardy-Weinberg equilibrium in both the patient and control groups as shown in Table 2. The demographic and clinical variables such as age, gender, BMI, education level, smoking and alcohol consumption, family history of cancer, endoscopic findings, and $\mathrm{H}$. pylori infection were assessed in both the study groups and correlation of the variables was also studied between the patient and control groups (Table 3 ).

In the current study, rapid urease test (RUT) was employed to investigate $\mathrm{H}$. pylori infection as an effective factor in GC development; 23 subjects from the control group (20.7\%) and 80 from patient group (88.9\%) were infected with $\mathrm{H}$. pylori. There was a significant difference between the two groups that may indicate the important role of $\mathrm{H}$. pylori in the etiology of gastric cancer.

Figures 1 and 2 show the result of electrophoresis after restriction enzyme digestion. After measuring the frequency of the mentioned SNP alleles, the following results were obtained: distribution of the genotypes for SNP-299 was $70.1 \%$ for AA, $27.4 \%$ for AG, and $2.5 \%$ for $\mathrm{GG}$ in the samples. The distributions of the genotypes for SNP-399 were $63.7 \%$ for CC, $34.3 \%$ for CT, and 2\% for TT. There was no significant association between SNP genotypes and pathological features (Table 4).

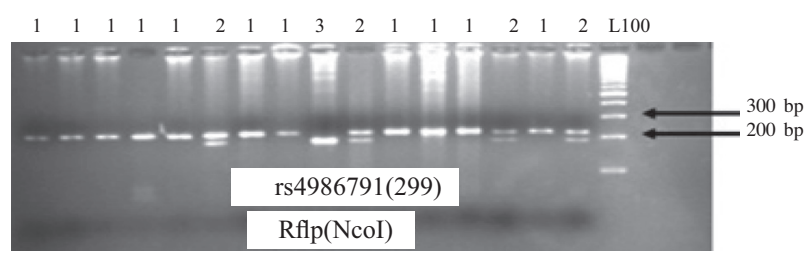

Figure 1: Results of NcoI Digestion Performing on 3\% Agarose Gel Electrophoresis

L100 = A100-bp DNA ladder, $\# 1=$ AA genotype, $\# 2=$ AG genotype, $\# 3=\mathrm{GG}$ genotype
Table 3: Demographic and Clinical Data of the Study Participants

\begin{tabular}{lccc}
\hline & $\begin{array}{c}\text { Patient } \\
(\text { No. }=90)\end{array}$ & $\begin{array}{c}\text { Control } \\
(\text { No. }=111)\end{array}$ & P Value \\
\hline Age, y & $49.30 \pm 15.50$ & $45.46 \pm 16.04$ & 0.000 \\
BMI, kg/m ${ }^{2}$, mean \pm & $26.68 \pm 4.79$ & $26.02 \pm 4.31$ & 0.438 \\
SD & & &
\end{tabular}

Gender, No. (\%)

$\begin{array}{lll}\text { Female } & 44(48.89) & 48(43.24) \\ \text { Male } & 46(51.11) & 63(56.76)\end{array}$

Smoking, No. (\%)

0.100

$\begin{array}{lrr}\text { Smoker } & 7(7.78) & 13(11.71) \\ \text { Non-smoker } & 78(86.67) & 96(86.49) \\ \text { Former smoker } & 5(5.55) & 2(1.80)\end{array}$

Alcohol Consumption,

No. (\%)

0.567

$\begin{array}{lrr}\text { Yes } & 5(5.55) & 4(3.60) \\ \text { No } & 85(94.45) & 107(96.40)\end{array}$

Cancer Family History,

No. $(\%)$

0.032

$\begin{array}{lll}\text { Yes } & 26(28.89) & 21(18.92) \\ \text { No } & 64(71.11) & 90(81.08)\end{array}$

\section{Education Level,}

No. (\%)

0.043

$\begin{array}{lrr}\text { No diploma } & 22(24.44) & 23(20.72) \\ \text { Diploma } & 34(37.78) & 40(36.04) \\ \text { Bachelor } & 29(32.22) & 39(35.13) \\ \text { Advanced } & 5(5.56) & 9(8.11)\end{array}$

H. pylori, No. (\%)

0.000

$\begin{array}{lll}\text { Positive } & 80(88.89) & 23(20.72) \\ \text { Negative } & 10(11.11) & 88(79.28)\end{array}$

Endoscopic Findings,

No. (\%)

0.000

\begin{tabular}{lrr} 
Normal & $10(11.11)$ & $73(65.77)$ \\
\hline Acute gastritis & $76(84.45)$ & $37(33.33)$ \\
Atrophic gastritis & $1(1.11)$ & $1(0.9)$ \\
Peptic ulcers & $3(3.33)$ & $0(0)$ \\
\hline
\end{tabular}

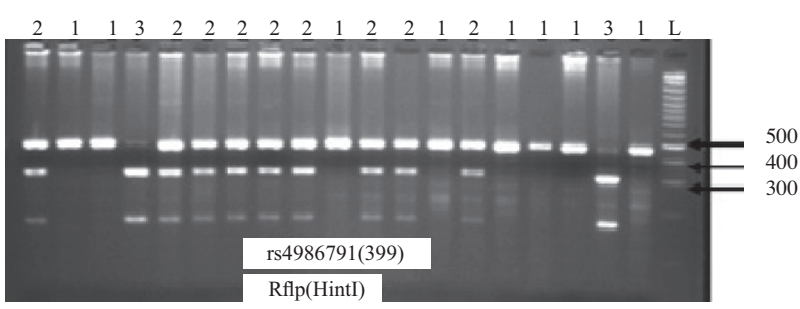

Figure 2: Results of HinfI Digestion Performing on 3\% Agarose Gel Electrophoresis

$\# 1=\mathrm{CC}$ genotype, $\# 2=\mathrm{CT}$ genotype, $\# 3=\mathrm{TT}$ genotype

\section{DISCUSSION}

$\mathrm{GC}$ is one of the most common causes of death worldwide and more than 700,000 people die from GC annually [23]. According to GLOBOCAN 2012, 
$\mathrm{GC}$ is the most common cancer among Iranian males and the second most common cancer among Iranian females [24]. In a previous meta-analysis, a significant correlation was reported between TLR4 polymorphisms (Asp299Gly and Thr399Ile) and the risk of GC [25]. Although the frequency of some alleles of TLR4 gene polymorphisms was different in the patients compared with the controls, no significant association was observed between gastric precancerous lesions and the expression of TLR 4 gene polymorphisms. TLR4 and NOD2/CARD15 genetic polymorphisms could be used to identify patients at greater risk for developing GC. It seems that TLR4 and NOD2/CARD15 genetic polymorphisms appear to play a role in gastric carcinogenesis [26]. No significant association was reported between TLR2 or TLR4 polymorphisms and the risk of gastric ulcer, duodenal ulcer, or atrophic gastritis [27]. In patients with H. pylori infection, TLR4 expression increased before treatment. However, after treatment with antibiotics and eradication of $\mathrm{H}$. pylori, there was a significant reduction in TLR4 gene expression [28]. H. pylori contribute to the development and progression of GC by various mechanisms. One of these mechanisms is the pathways associated with angiogenesis. In a previous study, it was observed that $\mathrm{H}$. pylori infection promoted angiogenesis via VEGF (vascular endothelial growth factor) upregulation [29]. In another study, Leng et al., observed that $\mathrm{H}$. Pylori infection had a role in early steps of GC development by increasing mitochondrial microsatellite instability (mtMSI) [30]. The current study results also confirmed this finding and suggested a potential role for $\mathrm{H}$. pylori in gastric carcinogenesis.

A previous study showed that TLR4 Thr399Ile polymorphisms were linked with increasing susceptibility to GC [17]. In a study performed on a Mexican population, it was observed that TLR4 Thr399Ile was associated with duodenal ulcer and GC [31], while in another study Garza-Gonzalez et al., observed no significant association with the risk of GC [32]. The current study evaluated the association between the abovementioned TLR4 polymorphisms in the case group and individual's clinical data. According to the results, no significant association was observed between Asp299Gly and Thr399Ile polymorphisms and endoscopic findings including gastric precancerous lesions and gastritis. These seemingly contradictory observations may be due to studies conducted in different populations since the frequency of single nucleotide polymorphisms varies in different populations. It seems that the correlation of the THR399ILE on the development of cancer is more than that of the ASP299GLY [33]. The current study examined the role of two polymorphisms of TLR4 gene in patients referred to Imam Reza Hospital. Although the frequency of the CC and CT alleles of THR399ILI, and that of AA and AG alleles of ASP299GLY were higher in the patient group, there were no significant correlations between the two TLR4 polymorphisms and various gastric precancerous lesions including acute gastritis, chronic gastritis metaplasia, and dysplasia. To further understand the role of this gene in the etiology of GC, further studies with larger sizes are recommended.

\section{ACKNOWLEDGMENTS}

The authors would like to express their deepest thanks to Drs. Khoshdel, Parvizi, Samizadeh, and Naseri, as well as all the personnel of Endoscopy Department of Imam Reza Hospital for their cooperation with the study.

\section{CONFLICT OF INTEREST}

The authors declared no conflict of interest.

\section{ETHICS APPROVAL}

The study protocol was approved by the Medical School Ethics Committee of Islamic Republic of Iran Army (AJA) University.

\section{REFERENCES}

1. Du Y-Y, Zhang Q-J, Sun G-P. Expression and Clinical Significance of Cytokeratin-19 and Thymidine Kinase-1 in Advanced Gastrointestinal Cancer. Chin Med J. 2016;129(18):2168-72. DOI: 10.4103/0366-6999.189919 PMID: 27625087.

2. García-Esquinas E, Pérez-Gómez B, Pollán M, Boldo E, Fernández-Navarro P, Lope V, et al. Gastric cancer mortality trends in Spain, 1976-2005, differences by autonomous region and sex. BMC Cancer. 2009;9(1):346. DOI: 10.1186/1471-2407-9-346 PMID: 19785726.

3. Stracci F, Canosa A, Minelli L, Petrinelli AM, Cassetti T, Romagnoli C, et al. Cancer mortality trends in the Umbria region of Italy 1978-2004: a joinpoint regression analysis. BMC Cancer. 2007;7(1):10. DOI: 10.1186/1471-2407-710 PMID: 17227578.

4. Kim JI, Kim SG, Kim N, Kim JG, Shin SJ, Kim SW, et al. Changing prevalence of upper gastrointestinal disease in 28893 Koreans from 1995 to 2005. Eur J Gastroenterol Hepatol. 2009;21(7):787-93. DOI: 10.1097/ MEG.0b013e32830e285a PMID: 19404205. 
5. Abdirad A, Ghaderi-Sohi S, Shuyama K, Koriyama C, Nadimi-Barforoosh H, Emami S, et al. Epstein-Barr virus associated gastric carcinoma: a report from Iran in the last four decades. Diagn Pathol. 2007;2(1):25. DOI: 10.1186/1746-1596-2-25 PMID: 17629938.

6. Frank B, Hoffmeister M, Klopp N, Illig T, Chang-Claude $\mathrm{J}$, Brenner H. Polymorphisms in inflammatory pathway genes and their association with colorectal cancer risk. Int J Cancer. 2010;127(12):2822-30. DOI: 10.1002/ijc.25299 PMID: 21351261.

7. Yoon H, Kim N. Diagnosis and Management of High Risk Group for Gastric Cancer. Gut Liver. 2015;9(1):5-17. DOI: 10.5009/gn114118 PMID: 25547086.

8. Nagashima H, Iwatani S, Cruz M, Jiménez Abreu JA, Uchida T, Mahachai V, et al. Toll-like receptor 10 in Helicobacter pylori infection. J Infect Dis. 2015;212(10):166676. DOI: $10.1093 /$ infdis/jiv270 PMID: 25977263.

9. Medzhitov R, Preston-Hurlburt P, Janeway CA. A human homologue of the Drosophila Toll protein signals activation of adaptive immunity. Nature. 1997;388(6640):394-7. DOI: $10.1038 / 41131$ PMID: 9237759.

10. Kutikhin AG. Impact of Toll-like receptor 4 polymorphisms on risk of cancer. Hum Immunol. 2011;72(2):193-206. DOI: 10.1016/j.humimm.2010.11.003 PMID: 21081146.

11. Rad R, Ballhorn W, Voland P, Eisenächer K, Mages J, Rad $\mathrm{L}$, et al. Extracellular and intracellular pattern recognition receptors cooperate in the recognition of Helicobacter pylori. Gastroenterol. 2009;136(7):2247-57. DOI: 10.1053/j. gastro.2009.02.066 PMID: 19272387.

12. Seya T, Shime H, Ebihara T, Oshiumi H, Matsumoto $\mathrm{M}$. Pattern recognition receptors of innate immunity and their application to tumor immunotherapy. Cancer sci. 2010;101(2):313-20. DOI: 10.1111/j.13497006.2009.01442.x PMID: 20059475.

13. El-Omar E, Ng M, Hold G. Polymorphisms in Toll-like receptor genes and risk of cancer. Oncogene. 2008;27(2):244. DOI: 10.1038/sj.onc.1210912 PMID: 18176606.

14. Pohjanen V-M, Koivurova O-P, Huhta H, Helminen O, Mäkinen JM, Karhukorpi JM, et al. Toll-like receptor 4 wild type homozygozity of polymorphisms +896 and + 1196 is associated with high gastrin serum levels and peptic ulcer risk. PloS One. 2015;10(7):e0131553. DOI: 10.1371/ journal.pone.0131553 PMID: 26161647.

15. Agúndez JA, García-Martín E, Devesa MJ, Carballo M, Martínez C, Lee-Brunner A, et al. Polymorphism of the TLR4 gene reduces the risk of hepatitis $C$ virus-induced hepatocellular carcinoma. Oncol. 2012;82(1):35-40. DOI: 10.1159/000335606 PMID: 22286521.

16. de Oliveira JG, Silva AE. Polymorphisms of the TLR2 and TLR4 genes are associated with risk of gastric cancer in a Brazilian population. World J Gastroenterol: WJG. 2012;18(11):1235. DOI: 10.3748/wjg.v18.i11.1235 PMID: 22468087.

17. Santini D, Angeletti S, Ruzzo A, Dicuonzo G, Galluzzo S, Vincenzi B, et al. Toll-like receptor 4 Asp299Gly and Thr399Ile polymorphisms in gastric cancer of intestinal and diffuse histotypes. Clin Exp Immunol. 2008;154(3):3604. DOI: 10.1111/j.1365-2249.2008.03776.x PMID: $\underline{18826495 .}$.

18. Chen J, Hu S, Liang S, Chen Q, Yang Q, Zheng W, et al. Associations between the four toll-like receptor polymorphisms and the risk of gastric cancer: a meta-analysis. Cancer Biother Radiopharm. 2013;28(9):674-81. DOI: 10.1089/cbr.2012.1395 PMID: 24007538.

19. Arbour NC, Lorenz E, Schutte BC, Zabner J, Kline JN, Jones $\mathrm{M}$, et al. TLR4 mutations are associated with endotoxin hyporesponsiveness in humans. Nat Genet. 2000;25(2):187. DOI: doi.org/10.1038/76048 PMID: 10835634.

20. Norata G, Garlaschelli K, Ongari M, Raselli S, Grigore L, Benvenuto F, et al. Effect of the Toll-like receptor 4 (TLR-4) variants on intima-media thickness and monocyte-derived macrophage response to LPS. J Intern Med. 2005;258(1):21-7. DOI: 10.1111/j.1365-2796.2005.01509.x PMID: 15953129.

21. Miller S, Dykes D, Polesky H. A simple salting out procedure for extracting DNA from human nucleated cells. Nucleic Acids Res. 1988;16(3):1215. DOI: 10.1093/ nar/16.3.1215 PMID: 3344216.

22. Rodriguez S, Gaunt TR, Day IN. Hardy-Weinberg equilibrium testing of biological ascertainment for Mendelian randomization studies. American journal of epidemiol. 2009;169(4):505-14. DOI: 10.1093/aje/kwn359 PMID: 19126586.

23. Ali Z, Mahmoodi M, Mohammad K, Zeraati H, Hosseini M, Naieni KH. Factors affecting the survival of patients with gastric cancer undergone surgery at iran cancer institute: Univariate and multivariate analyses. Iran J Public Health. 2014;43(6):800.

24. Ferlay J, Soerjomataram I, Dikshit R, Eser S, Mathers C, Rebelo $\mathrm{M}$, et al. Cancer incidence and mortality worldwide: sources, methods and major patterns in GLOBOCAN 2012. Int J Cancer. 2015;136(5). DOI: 10.1002/ ijc.29210 PMID: 25220842.

25. Zhao X, Kang S, Liu L, Zhang D. Correlation of Asp299Gly and Thr399Ile polymorphisms in toll-like receptor 4 gene with digestive cancer risk: A meta-analysis. Biomed Rep. 2013;1(2):294-302. DOI: 10.3892/br.2012.32 PMID: 24648938 .

26. Rigoli L, Di Bella C, Fedele F, Procopio V, Amorini M, Giudice GL, et al. TLR4 and NOD2/CARD15 genetic polymorphisms and their possible role in gastric carcinogenesis. Anticancer Res. 2010;30(2):513-7. PMID: 20332463.

27. Suzuki T, Meguro A, Matsushima M, Masui A, Tsuda S, Nakamura J, et al. Investigation of the Association of TLR2 and TLR4 Polymorphisms with Susceptibility to Helicobacter pylori-Related Gastrointestinal Diseases. Open J Intern Med. 2014;4(04):130. DOI: 10.4236/ojim.2014.44020.

28. Cadamuro ACT, Rossi AFT, Maniezzo NM, Silva AE. Helicobacter pylori infection: host immune response, implications on gene expression and microRNAs. World J Gastroenterol: WJG. 2014;20(6):1424. DOI: 10.3748/wjg.v20. i6.1424 PMID: 24587619.

29. Liu N, Zhou N, Chai N, Liu X, Jiang H, Wu Q, et al. Helicobacter pylori promotes angiogenesis depending on Wnt/ beta-catenin-mediated vascular endothelial growth factor via the cyclooxygenase-2 pathway in gastric cancer. BMC Cancer. 2016;16(1):321. DOI: 10.1186/s12885-016-2351- 
9 PMID: 27198692.

30. Ling X, Zhang H, Shen C, Yan W, Wang P, Feng J, et al. H. pylori infection is related to mitochondrial microsatellite instability in gastric carcinogenesis. Infect Agent Cancer. 2016;11(1):30. DOI: 10.1186/s13027-016-0078-5 PMID: 27408617.

31. Torres J, Pérez-Rodríguez M, Camorlinga-Ponce M, Luna LF, Abdo-Francis JM, Lazcano E, et al. TLR4 single-nucleotide polymorphisms alter mucosal cytokine and chemokine patterns in Mexican patients with Helicobacter pylori-associated gastroduodenal diseases. Clin Immunoly. 2008;129(2):333-40. DOI: 10.1016/j.clim.2008.07.009
PMID: 18755634.

32. Garza-Gonzalez E, Bosques-Padilla FJ, Mendoza-Ibarra SI, Flores-Gutierrez JP, Maldonado-Garza HJ, Perez-Perez GI. Assessment of the toll-like receptor 4 Asp299Gly, Thr399Ile and interleukin-8-251 polymorphisms in the risk for the development of distal gastric cancer. BMC Cancer. 2007;7(1):70. DOI: 10.1186/1471-2407-7-70 PMID: 17462092.

33. Ding L, Jiang Q, Li G, Shen J, Du J, Lu X, et al. Comprehensive assessment of association between TLR4 gene polymorphisms and cancer risk: a systematic meta-analysis. Oncotarget. 2017;8(59):100593. DOI: 10.18632/oncotarget.21543 PMID: 29246004. 